\title{
The relationship between learner-centered teaching and learning motivation among nursing students in Minia University
}

\author{
Abeer Mohamed Abdelkader*1, Naglaa Mohamed Amin ${ }^{2}$, Aishah Almefarfesh ${ }^{3}$ \\ ${ }^{1}$ Nursing Education Department, Minia University, Egypt \\ ${ }^{2}$ Community Health Nursing Department, Faculty of Nursing, El-Minia University, Egypt \\ ${ }^{3}$ MCPHS University, USA
}

Received: April 7, 2019

DOI: $10.5430 /$ jnep.v9n10p42
Accepted: June 30, 2019

Online Published: July 12, 2019

\begin{abstract}
Background and objective: One of the important goals of nursing education is to motivate nurses to acquire skills for providing proper quality of health care services to clients with various complex health problems. Accomplishing this has challenged educational organizations for long years. The aim of the present study is to identify the relationship between Learner-Centered Teaching and learning motivation among Nursing Students in Minia University.

Methods: A quantitative-correlational research design was utilized in the present study. The study sample comprised all fourth-year nursing students who were available at the time of data collection $(\mathrm{N}=168)$. For the assessment of Learner-Centered Teaching Practices and learning motivation, a questionnaire developed by Rossi (2009) was used for data collection.

Results: The study participants reported their highest mean scores about learner-centered teaching practices with three domains as follows: facilitates the learning process, provides for individual and social learning needs, and establishes positive interpersonal relationships. Also, they expressed highest mean scores about learning motivation with intrinsic motivation factors. Additionally, the study findings presented high statistical significant difference and fair positive relationship between all subscales of learnercentered teaching practices and intrinsic motivation factors ( $p$ value $=.001)$.

Conclusions: Nursing curriculum should include learner as active contributors in the learning process. When nurse educators give a lecture and encourage students to interact actively with ideas, and information after the lecture, this will motivate students to be an active learner, as well as, inspire innovative thinking and creativity of the students.
\end{abstract}

Key Words: Learning motivation, Active teaching, Nursing students

\section{INTRODUCTION}

One of the important goals of nursing education is to motivate nurses to acquire skills for providing proper quality of health care services to clients with various complex health problems. Accomplishing this has challenged educational organizations for many years. ${ }^{[1,2]}$ Also, Nursing students are expected to work independently and competently after their graduation and should be prepared to handle their diverse professional roles efficiently. In the educational setting, the most important barrier to successful learning is students' lack of interest and motivation. ${ }^{[3,4]}$ Nursing students require longterm motivation to help others in the future. Thus focusing

\footnotetext{
*Correspondence: Abeer Mohamed Abdelkader; Email: beronlyosman@mu.edu.eg; Address: Nursing Education Department, Minia University,
} Egypt. 
to the concept of motivation is very important in educational setting. ${ }^{[5]}$

Learning Motivation in the present study was defined in terms of both intrinsic (pushed from in the learner) and extrinsic (teacher- and overall performance-pushed) ${ }^{[6]}$ The four intrinsic factors are: First, the students' ideals in self-competency to examine and obtain; second, the students' techniques in being actively engaged whilst acquiring knowledge; third, the students' information-in search of curiosity in mastering, and fourth, the students' intrinsic motivation orientation directed to mastering and studying project dreams. ${ }^{[7]}$ The three extrinsic factors are; first is the learners' behaviors directed at heading off attempt even as mastering; second is the students' extrinsic motivation orientation directed to accomplishing high grades or ratings rather than studying, and third is the students' motivational orientation directed to avoiding assignments and other work concerned in mastering. ${ }^{[8,9]}$

Learning motivation described as an important factor in effective nursing performance. Also, motivation plays a significant role in clarifying of behaviors, predicting effects of actions and directing behavior to fulfill goals. When students are motivated during the learning process, everything will be well, creativity and learning will be more open, stress will decrease and relationships will run smoothly. Hassankhani et al. (2015) conducted a descriptive-correlational study with the aim of investigating the relationship between learning motivation and self-efficacy among the nursing students; it was carried out at Tabriz University of Medical Sciences. Data was gathered from 125 nursing students who participated in the study. Their study results showed that an increase in learning motivation could be associated with the promotion of self-efficacy in professional nursing competency in nursing students. ${ }^{[10,11]}$

Nursing education is an integrated combination of classroom and clinical learning experiences which offering knowledge, skills and attitudes to students for professional practice. The complex combination of competence, problem-solving skills, psychomotor skills, and knowledge is fundamental for nursing practice. ${ }^{[12,13]}$ Learner-centered methods require learners to take responsibility for their learning by actively participating in active learning strategies rather than simply receiving information passively. The strategies used may include group work, role-play, class presentations, and case studies. These strategies have been shown to improve critical thinking skills, retention and post-graduate success. ${ }^{[14]}$

Wright (2011) stated that today's students are "unable to work without structure and imposed control" and having "little or no commitment to learning". Their concern is to have a good score, and when this does not happen the teacher is blamed. Moreover, Ellis (2016) conducted a study with the sample of 122 nursing educators using an online survey for data collection to investigate the role of nurse educators' beliefs and self-perception in their use of learner-centered teaching. The findings of his study provide an evidence of the role of self-perception and beliefs about learner-centered teaching, and the impact this may be on the actual use of learner-centered teaching. It is obvious that the valuing of learner-centered learning and the belief in its effectiveness is only part of the answer to convincing nursing educators to adopt this teaching framework on a large scale. ${ }^{[14,15]}$

Also, Fan \& Feng (2012) conducted a study to understand students' motivation to learn English as a foreign language. The study participants were 109 students (all authors' classrooms) at the Pingtung National Institute of Commerce. The study focused on learning motivation among students in vocational schools in Taiwan. The findings of the study found that motivation to learn is the main factor in learning English as a foreign language. The results also showed that there is a stronger statistical significance between learning motivation and learning achievement, but there is little statistical significance between learning motivation and learning needs. ${ }^{[6]}$

Moreover, Lee, Chuan, and Chang (2014) conducted a study to identify the association between motivation, achievement and satisfaction of nursing staff before and after training program in Excel Visual Basic for Applications. The research sample was 33 volunteer nurses. The findings revealed that after the training program, the participants had better knowledge of Excel Visual Basic for Applications and higher learning motivation. Furthermore, Pramilaa (2016) conducted a study for assessment of self-motivation among bachelor nursing students. The number of participants was 80; twenty students were selected from the first year to the fourth by simple random sampling. His results showed that self- motivation happens in the absence of rewards or external incentives, and thus can be a powerful indicator that the learner has become more independent. Thus, the role of nursing educator should be expanded sufficiently to explore the self-motivation ability of nursing students at the time of admission. ${ }^{[16,17]}$

College of nursing at Minia University support learnercentered approaches to teaching at all levels of education. Number of students is 1,630 and number of faculty members is 124 with 1:13 faculty -to- student ratios. Fourth year nursing students in Minia University study three major nursing courses titled as community health nursing, Psychiatric Nursing and Mental Health, and nursing administration. They practice different academic activities in the class room and 
clinical setting such as but not limited to case study presentation, client assignment, and nursing care plan development. Even though students experience active participation in their learning process many of them come to the class or clinical setting late. Also, sometimes go out early or ask to extend the due date of a required assignment.

Students should be encouraged to study. If students aren't stimulated, they may not learn. Knowledge about students' motivation may help educators determine which students are likely to participate in and benefit from the teachinglearning process. In addition, an understanding of learners' motivation is the key for effective instructional design. ${ }^{[18,19]}$ However, we know little about the motivational beliefs and learning experiences of nursing education in Minia University. The researcher could not find a study that examines the learning motivation and learner-centered teaching among Minia Nursing Students. Therefore, the present study was carried out with the aim of identify the relationship between Learner-Centered Teaching and learning motivation among Nursing Students in Minia University.

\subsection{Aim of the study}

The present study aims to identify the relationship between nursing students' perceptions of their learner-centered teaching practices and their perceptions of learning motivation.

\section{SubJECTS AND METHOd}

\subsection{Research design}

A quantitative-correlational research design was utilized in the present study.

\subsection{Setting}

The study was conducted at College of Nursing in Minia University, Egypt.

\subsection{Subjects}

The study sample comprised all fourth year nursing students who were available at the time of data collection $(\mathrm{N}=168)$.

\subsection{Sampling}

A convenient sampling method was used to select the study sample.

\subsection{Tool of data collection}

Assessment of Learner-Centered teaching Practices and learning motivation questionnaire was used for data collection. ${ }^{[1]}$ Self-administered questionnaire was used and subjects have 10-15 minutes to complete it. The questionnaire is composed of 71 items, each item was scored according to a 5-point Likert scale ranges from 1 (strongly disagree) to
5 (strongly agree) to assess their perceived level of LearnerCentered teaching Practices and learning motivation. Where one for strongly disagree, two for disagree, three for undecided, four for agree, and five for strongly agree. The questionnaire is scored by adding the items on each of the subscales. The questionnaire is consisted of three parts as follow:

Part I: Sociodemographic variables such as age, gender, previous academic achievement, and place of residence.

Part II: Learner-Centered Teaching Practices scale (23 items) subdivided into 5 subscales as 1) Establishes positive interpersonal relationships (5 items); 2) Facilitates the learning process (7 items); 3) Adapts to class learning needs (4 items); 4) Encourages personal challenge and responsibility (3 items); and 5) Provides for individual and social learning needs (5 items). The study participants' responses calculated as follows; low levels of Learner-Centered Teaching Practices are a score below 40, moderate levels range from 41 to 80 , and high levels are score more than 80 .

Part III: Learning Motivation scale (35 items) subdivided into two subscales as intrinsic motivation (20 items) and extrinsic motivation (15 items). The four intrinsic factors were: 1) Self-efficacy (5 items); 2) Knowledge-seeking curiosity (5 items); 3) Active learning strategies (5 items); and 4) Task mastery goals (5 items); the three extrinsic student motivation factors were: 1) Effort avoidance strategies (5 items); 2) Performance-oriented goals (5 items); and 3) Work avoidance goals (5 items). The study participants' responses calculated as follows; low levels of Learning Motivation are a score below 58, moderate levels range from 59 to 116 , and high levels are score more than 116.

\subsection{Procedures}

(1) Validation of the tool was done by four specialists in the related field as follows; two professors from Nursing Education department at Faculty of Nursing in Alexandria University, two professors from Nursing Administration department at Faculty of Nursing in Minia University. Reliability of the tool was calculated using Alpha reliability coefficients $r=$ 0.89 .

(2) To examine and ensure the clarity and applicability of the study tool, a pilot study was conducted on a sample of ten percent from participants (17 students). Based on pilot results necessary corrections of the tool were done. The subjects of the pilot were not included in the main subjects of the study.

(3) The study participants were invited to fill in the full questionnaire (10-15 $\mathrm{min})$. 
(4) Data were collected from 20 March to 30 April 2016.

\subsection{Ethical consideration}

The permission to conduct the study was obtained from all responsible authorities of Minia Faculty of nursing (the dean and heads of departments) after explanation of the study purpose. Also, fourth year nursing students were informed regarding the purpose of the present study. After having expressed their consent, they were free to participate. In addition, confidentiality, privacy, and anonymity of the participants and their responses were assured.

\subsection{Statistical analysis}

The collected data were entered and analyzed using statistical package for the social sciences software (SPSS) for Windows (version 20). Data presented using descriptive statistic in the form of frequency and percentage. Also, Pearson correlation, mean, standard deviation, $\mathrm{f}$ test, and $t$-test were calculated to evaluate the relationship between variables. $p$ value of $\leq .05$ was utilized to calculate the significance of the results.

\section{RESUlts}

Table 1 revealed that $42.9 \%$ of the student aged 23 years old, $81.5 \%$ are female, $51.2 \%$ achieved very good grades in the previous academic achievement, and $83.3 \%$ of them lived in rural areas.

Table 2 shows the mean scores of the study participants' perception of learner-centered teaching practices. It was observed that the study participants expressed their highest perception with teaching practices domains named as facilitates the learning process, provides for individual and social learning needs and establishes positive interpersonal relationships $(29.2 \pm 3.1,20.1 \pm 2.4$, and $16.1 \pm 1.7)$ respectively. On the other hand, they reported their lowest perception mean scores with teaching practices domains named as Adapts To Class Learning Needs and Encourages Personal Challenge and Responsibility $(3.8 \pm 1.1,5.8 \pm 2.2)$ respectively.

Table 1. Distribution of the study participants according to their general characteristics $(\mathrm{N}=168)$

\begin{tabular}{lll}
\hline General Characteristic & No & \% \\
\hline Age & \multicolumn{2}{l}{} \\
22 & 68 & 40.5 \\
23 & 72 & 42.9 \\
24 & 22 & 13.1 \\
25 & 6 & 3.5 \\
Mean \pm S.D & $22.8 \pm 3.8$ years \\
Gender & \multicolumn{2}{|c}{} \\
Male & 31 & 18.5 \\
Female & 137 & 81.5 \\
Previous academic achievement & \multicolumn{2}{|c}{} \\
Excellent & 75 & 44.6 \\
Very good & 86 & 51.2 \\
Good & 7 & 4.2 \\
Residence & & \\
Rural & 140 & 83.3 \\
Urban & 28 & 16.7 \\
\hline
\end{tabular}

Table 2. Mean score of the study participants' perceptions about Learner-Centered Teaching Practices $(\mathrm{N}=168)$

\begin{tabular}{|c|c|c|c|c|c|}
\hline \multirow{3}{*}{ Learner-centered teaching practices domains } & \multicolumn{3}{|c|}{ Learner-Centered Teaching Practices levels } & \multirow{3}{*}{$\mathbf{F}$} & \multirow{3}{*}{$p$-value } \\
\hline & Low $(<40)$ & Moderate (41-80) & High $(>80)$ & & \\
\hline & Mean \pm S.D & Mean \pm S.D & Mean \pm S.D & & \\
\hline Establishes Positive Interpersonal Relationships & $6.5 \pm 1.9$ & $12.1 \pm 2.3$ & $16.1 \pm 1.7$ & 9.1 & $.001 *$ \\
\hline Facilitates the Learning Process & $11.8 \pm 1.7$ & $21.4 \pm 4.0$ & $29.2 \pm 3.1$ & 20.6 & $.001 *$ \\
\hline Adapts To Class Learning Needs & $3.8 \pm 1.1$ & $8.6 \pm 2.3$ & $12.1 \pm 1.7$ & 7.5 & $.001 *$ \\
\hline Encourages Personal Challenge and Responsibility & $5.8 \pm 2.2$ & $9.4 \pm 1.7$ & $12.2 \pm 1.4$ & 6.9 & $.001 *$ \\
\hline Provides for Individual and Social Learning Needs & $9.8 \pm 1.3$ & $14.8 \pm 2.6$ & $20.1 \pm 2.4$ & 10.8 & $.001 *$ \\
\hline
\end{tabular}

*Significant at $p \leq .05$.

Table 3 demonstrated the mean scores of the study participants' perceptions about their learning motivation. It was clears that, statistically significant differences $(p=.0001)$ existed between all learning motivation factors levels except work avoidance goals factor. Moreover, the same table shows that the study participants' perceptions about their learning motivation reported their highest mean scores with their intrinsic motivation factors rather than their extrinsic motiva- tion factors. In addition, this table demonstrates that the highest mean scores reported with task mastery goals, active learning strategies followed by self-efficacy and knowledgeseeking curiosity $(20.3 \pm 2.7,20.1 \pm 2.3,19.9 \pm 2.3$, and $19.3 \pm 2.7$ respectively).

Table 4 illustrated the presence of statistical significant difference and fair positive relationship among all subscales of learner-centered teaching practices and intrinsic motivation 
factors $(p$ value $=.001)$. Also, the same table illustrates sta- strategies. On the other hand, the present table showed neitistical significant difference and weak positive relationship ther statistical significant difference nor correlation among all between all subscales of learner-centered teaching practices subscales of learner-centered teaching practices and extrinsic and extrinsic motivation factor named as effort avoidance motivation factor named as work avoidance goals.

Table 3. Mean score of the study participants' perceptions about Learning Motivation $(\mathrm{N}=168)$

\begin{tabular}{|c|c|c|c|c|}
\hline \multirow{3}{*}{ Item } & \multicolumn{2}{|c|}{ Learning Motivation levels } & \multirow{3}{*}{$t$} & \multirow{3}{*}{$p$-value } \\
\hline & Moderate (59-116) & High $(>116)$ & & \\
\hline & Mean \pm S.D & Mean \pm S.D & & \\
\hline \multicolumn{5}{|l|}{ Intrinsic Motivation Factors } \\
\hline Self-efficacy & $15.4 \pm 3.3$ & $19.9 \pm 2.3$ & 8.539 & $.0001 *$ \\
\hline Knowledge-seeking curiosity & $15.1 \pm 2.6$ & $19.3 \pm 2.7$ & 7.572 & $.0001 *$ \\
\hline Active learning strategies & $16.1 \pm 2.8$ & $20.1 \pm 2.3$ & 8.264 & $.0001^{*}$ \\
\hline Task mastery goals & $16.4 \pm 2.9$ & $20.3 \pm 2.7$ & 6.950 & $.0001^{*}$ \\
\hline \multicolumn{5}{|l|}{ Extrinsic Motivation Factors } \\
\hline Effort avoidance strategies & $13.8 \pm 2.9$ & $16.5 \pm 2.4$ & 5.209 & $.0001 *$ \\
\hline Performance-oriented goals & $15.2 \pm 3.1$ & $17.7 \pm 3.2$ & 3.736 & $.0001 *$ \\
\hline Work avoidance goals & $16.1 \pm 2.7$ & $17.3 \pm 3.1$ & 2.149 & $.03 *$ \\
\hline
\end{tabular}

*Significant at $p \leq .05$.

Table 4. Pearson correlation of learner-centered teaching practices and Learning Motivation of the study participants $(\mathrm{N}=$ 168)

\begin{tabular}{|c|c|c|c|c|c|c|c|c|c|c|}
\hline \multirow{3}{*}{$\begin{array}{l}\text { Learning Motivation } \\
\text { Factors }\end{array}$} & \multicolumn{10}{|c|}{ Learner-centered teaching practices } \\
\hline & \multicolumn{2}{|c|}{$\begin{array}{l}\text { Establishes } \\
\text { Positive } \\
\text { Interpersonal } \\
\text { Relationships }\end{array}$} & \multicolumn{2}{|c|}{$\begin{array}{l}\text { Facilitates the } \\
\text { Learning } \\
\text { Process }\end{array}$} & \multicolumn{2}{|c|}{$\begin{array}{l}\text { Adapts to Class } \\
\text { Learning Needs }\end{array}$} & \multicolumn{2}{|c|}{$\begin{array}{l}\text { Personal } \\
\text { Challenge and } \\
\text { Responsibility }\end{array}$} & \multicolumn{2}{|c|}{$\begin{array}{l}\text { Provides for } \\
\text { Individual and } \\
\text { Social Learning } \\
\text { Needs Encourages }\end{array}$} \\
\hline & $r$ & $p$-value & $r$ & $p$-value & $r$ & $p$-value & $r$ & $p$-value & $r$ & $p$-value \\
\hline \multicolumn{11}{|l|}{ Intrinsic Motivation Factors } \\
\hline Self-efficacy & .268 & $.001 *$ & .272 & $.001 *$ & .287 & $.001 *$ & .246 & $.001 *$ & .329 & $.001 *$ \\
\hline Knowledge-seeking curiosity & .253 & $.001 *$ & .315 & $.001 *$ & .335 & $.001 *$ & .223 & $.004 *$ & .283 & $.001 *$ \\
\hline Active learning strategies & .375 & $.001 *$ & .406 & $.001 *$ & .377 & $.001 *$ & .372 & $.001 *$ & .388 & $.001 *$ \\
\hline Task mastery goals & .368 & $.001 *$ & .450 & $.001 *$ & .384 & $.001^{*}$ & .407 & $.001^{*}$ & .450 & $.001^{*}$ \\
\hline \multicolumn{11}{|l|}{ Extrinsic Motivation Factors } \\
\hline Effort avoidance strategies & .230 & $.003 *$ & .204 & $.008 *$ & .237 & $.002 *$ & .237 & $.002 *$ & .161 & $.04 *$ \\
\hline Performance-oriented goals & .182 & $.02 *$ & .132 & .09 & .143 & .06 & .073 & .348 & .239 & $.002 *$ \\
\hline Work avoidance goals & .1 & .197 & .062 & .423 & .053 & .496 & .079 & .306 & .060 & .443 \\
\hline
\end{tabular}

*Significant at $p \leq .05$. Spearmen Rho correlation coefficient $r=0.00$ to 0.24 weak or no correlation; $r=0.25$ to 0.49 Fair correlation; $r=0.50$ to 0.74 moderate correlation; $r=0.75+$ strong correlation.

\section{Discussion}

Competency of nursing students is an essential element for providing safe and quality of nursing practice. Therefore, nursing students need broad-based preparations that include a wide scope of knowledge and skills from nursing and other related fields to meet the complex client needs. ${ }^{[5]}$ Hadi et al. (2015) explained that students' academic performance is affected by many factors, including motivation, which may be easily ignored. It is necessary, however, for nursing educators, managers and consultants to examine motivation in their students. ${ }^{[20]}$

The present study finding revealed that the highest perception with learner-centered teaching practices domains named as facilitates the learning process, provides for individual and social learning needs and establishes positive interpersonal relationships. With regard to this finding, Cheng et al. (2010) stated: nursing educator design best lesson plans and curriculum, and implement relevant teaching activities for nursing students in order to enhance the growth of lifelong learning abilities. ${ }^{[21]}$ Moreover, this finding was supported 
by Bayram \& Hayırsever (2016) who stated that: the teacher acts a facilitator and supervisor in student-centered learning. Also, the relationship between students is more equal and supports emotional and cognitive areas development. ${ }^{[22]}$

Furthermore, the study finding shows the highest mean scores with the intrinsic motivation factors rather than the extrinsic motivation factors. This result agrees with Cadorin et al. (2017). They clarified that: in the healthcare field, learning motivation is considered as a basic principle for lifelong learning, learning motivation comprises both entry and task motivation: the first determines the learner's commitment to a specific purpose and intention to act at the beginning; and the second measures the learner's tendency to focus on and continue in learning activities and purposes. Finally, volition is part of the learning motivation, determining the learners' ability to activate intentional efforts and diligence that may influence persistence in learning. ${ }^{[23]}$

In addition, this study demonstrates that the highest mean scores reported with task mastery goals, active learning strategies followed by self-efficacy and knowledge-seeking curiosity. In relation to this finding Rossi (2009) mentioned that students who are intrinsically motivated are those who learn for the pleasure of learning and who have a sense of selfdetermination about their education. Intrinsic motivation has been shown to foster conceptual understanding, creativity, involvement, and a preference for challenge. Research on college student learning indicates that students with an intrinsic orientation are more likely to use cognitive strategies such as elaboration and organization, resulting in deeper processing of the material. ${ }^{[1]}$

Similarly, this result agrees with Pramilla (2016) who said that Self-motivation happens within the absence of outside rewards or incentives and can consequently be sturdy indicator that a learner is becoming more independent. He examine the self-motivation for all Bachelor nursing students; first, second, third, and fourth academic year. His findings highlight that the students do possess self-motivation. ${ }^{[17]}$

Moreover, this finding matches with Hadi (2015) who said that motivation performs an essential role in clarifying of behaviors, expecting outcomes of activities and directing conduct to obtain goals. also, motivation no longer simplest stimulates learning, but is also an intermediate to studying; even as students have motivation in the process of the learning technique, the entirety will be paved nicely, relationships will run easily, stress will lower and creativity and gaining knowledge of can be more open. ${ }^{[20]}$

Additionally, this study illustrated the presence of high statistical significant difference and fair positive relationship

Published by Sciedu Press between all subscales of learner- centered teaching practices and intrinsic motivation factors. This outcome supported by Clayton (2010) who recommended that the level of engagement of the student and the several teaching strategies used to adjust the variety learning styles of participants and the possibility for spontaneous and stay discussions. These factors also are regularly stated as critical features of a learning environment that fosters mastery purpose ${ }^{[19]}$ Moreover, this result is in the line with Fan \& Feng (2012). He stated that students who attribute their success or failure to effort or learning strategies instead of to their perception of their potential, success and/or challenge difficulty may be greater keen to study and search for knowledge and will no longer give up easily. ${ }^{[6]}$

Furthermore, this result seems to be in agreement with Yoo, Park, and Lee (2010) who examined the effect of case based learning (as learner-centered teaching method) on students motivation and found high impact in enhancing clinical decision-making and motivating students to learn by encouraging self-directed learning and creating more interest and curiosity in learning. ${ }^{[24]}$ Similarly, Yoo and Chae (2011) investigated the effect of peer review (as learner-centered teaching) on communication skills and learning motivation. Their result shows that peer review is an effective learning method for nursing students to increase their communication skills and promote their motivation to learn. ${ }^{[25]}$

To effectively develop the knowledge, skills and competencies expected of nursing students, the current findings support the evidence that learner-centered teaching linked to increasing motivation at all levels of education. ${ }^{[13]}$ On the other hand, the current study has a limitation of a convenience sample and this may threaten the generalizability of the findings.

\section{Conclusions}

The evidence of the present study shows that learner-centered teaching lead to promoting the highest levels of motivation and accomplishment. Nursing curriculum should include learner as active contributors in the learning process. When nurse educator give a lecture and encourage students to interact actively with ideas, and information after the lecture, this will motivate students to be an active learner, as well as, inspire innovative thinking and creativity of the students.

\subsection{Recommendations for practice}

(1) Further attention should be given to helping professors and students understand the benefits of using different teaching approaches and the benefits of learningcentered teaching methods.

(2) Motivate the learner by providing them with the con- 
structive feedback.

(3) The educational institutions should also create supportive atmospheres that will encourage learners to engage actively with their instructors and maximize the achievement of educational goals.

(4) Using learner-centered teaching strategies and approaches is related to making students feel connected to classroom and adding human dimensions to the classroom.

\subsection{Recommendations for future research}

(1) Replication of the study with a larger sample to increase the generalizability of the findings.
(2) Further researches should be conducted to identify how students perceive differences in the learning process based on different learner-centered teaching approaches. Also, student academic achivement should be compared across the different learner-centered teaching practices.

\section{CONFlicts OF INTEREST Disclosure}

There was no conflict of interest during conducting this study.

Theory Study. Nursing Research and Practice. 2012; 1(10): 1-7. PMid:22830005 https ://doi .org/10.1155/2012/161359

[12] Stephenson T, Peritore N, Webber K, et al. A Learner-Centered Teaching Model Integrating Undergraduate Research and Service Learning. NACTA Journal. 2013.

[13] Pasque S, Tricomi E. Effects of intrinsic motivation on feedback processing during learning. Neuro Image. 2015; 119(1): 175-186. PMid:26112370 https://doi.org/10.1016/j.neuroimage. 2 015.06 .046

[14] Wright G. Student-Centered Learning in Higher Education. International Journal of Teaching and Learning in Higher Education. 2011; 23(3): 92-97.

[15] Ellis M. The role of nurse educators' self-perception and beliefs in the use of learner-centered teaching in the classroom. Nurse Education in Practice. 2016; 16: 66-70. PMid:26387838 https: //doi.org/10.1016/j.nepr.2015.08.011

[16] Lee Y, Chuan M, Chang P. The Relationship of Learning Motivation,Achievement and Satisfaction for Nurses Learning Simple Excel VBA Information Systems Programming. Nursing Informatics. 2014; 1(1): $364-370$.

[17] Pramilaa P. Self Motivation among B.Sc Nursing Students A Comparative Study. International Journal of Nursing Education. 2016; 8(3): 82-86. https://doi.org/10.5958/0974-9357.2016.0 0097.0

[18] Salili F, Chiu C, Hong Y. Student Motivation The Culture and Context of Learning. 1st ed. Hong Kong: Springer; 2001. https : //doi.org/10.1007/978-1-4615-1273-8_1

[19] Clayton K. The relationship between motivation, learning strategies and choice of environment whether traditional or including an online component. British Journal of Educational Technology. 2010; 41(3): 349-364. https://doi.org/10.1111/j.1467-8535.20 09.00993.x

[20] Hadi H, Rahmani A, Mohammad Z. The Relationship between Learning Motivation and Self Efficacy among Nursing Students. Res Dev Med Educ. 2015; 4(1): 97-101. https://doi.org/10.15171/r dme.2015.016

[21] Cheng SF, Kuo CL, Lin KC, et al. Development and preliminary testing of a self-rating instrument to measure self-directed learning ability of nursing students. Int J Nurs Stud. 2010; 47(9): 1152-8. PMid:20223455 https://doi.org/10.1016/j.ijnurstu. 201 0.02 .002 
[22] Bayram D, Hayırsever F. Student-centred Learning: How Does It Work in Practice? British Journal of Education, Society \& Behavioural Science. 2016; 18(3): 1-16. https ://doi.org/10.973 4/BJESBS/2016/28810

[23] Cadorin L, Ghezzi V, Camillo M, et al. The self-rating scale of selfdirected learning tool. Journal of Nursing Education and Practice. 2017; 7(2): 31-37.

[24] Yoo MS, Park JH, Lee SR. The Effects of Case-Based Learning
Using Video on Clinical Decision Making and Learning Motivation in Undergraduate Nursing Students. J Korean Acad Nurs. 2010; 40(6): 863-871. PMid:21336020 https://doi .org/10.4040/jk an. 2010.40.6.863

[25] Yoo MS, Chae SM. Effects of peer review on communication skills and learning motivation among nursing students. J Nurs Educ. 2011; 50(4): 230-3. PMid:21323255 https://doi .org/10.3928/0148 4834-20110131-03 